
SYSTEMIC LUPUS ERYTHEMATOSUS: DATA FROM THE SPANISH RHEUMATOLOGY SOCIETY LUPUS REGISTRY (RELESSER) COHORT

J. Narvaez ${ }^{1}$, H. Borrell ${ }^{1}$, F. Sánchez-Alonso ${ }^{2}$, I. Rúa-Figueroa ${ }^{3}$, F.J. Lopez-Longo ${ }^{4}$, M. Galindo ${ }^{5}$, J. Calvo-Alen ${ }^{6}$, A. Fernández-Nebro ${ }^{7}$, A. Olivé ${ }^{8}$, J.L. Andreu ${ }^{9}$, R. Blanco ${ }^{10}, M$. Andres ${ }^{11}$, J.J. Alegre ${ }^{12}$, T. Cobo-lbañez ${ }^{13}$, G. Bonilla $^{14}$, A. Boteanu ${ }^{15}$, E. Díez-Álvarez ${ }^{16}, M$. Freire ${ }^{17}, M$. Gantes $^{18}$, P. Garcia de la Peña ${ }^{19}$, R. Garcia-Vicuña ${ }^{20}$, J. Hernández Beiraín ${ }^{21}$, M.L. Horcada ${ }^{22}$, J. Ibañez ${ }^{23}$, A. Juan $\mathrm{Mas}^{24}$, N. Lozano-Rivas ${ }^{25}$, J.L. Marenco ${ }^{26}$, I. Castelvi2 ${ }^{27}$, C. Montilla-Morales ${ }^{28}$, M. Moreno ${ }^{29}$, A. Pecondon-Españo ${ }^{30}$, E. Ruiz Lucea ${ }^{31}$, A. Sanchez-Atrio ${ }^{32}$, G. Santos-Soler ${ }^{33}$, F. Toyos ${ }^{34}$, E. Uriarte Isacelaya ${ }^{35}$, T.R. Vazquez-Rodriguez ${ }^{36}$, J.M. Nolla ${ }^{1}$, J.M. Pego-Reigosa ${ }^{37}$ on behalf of EAS-SER (Systemic Diseases Study Group of the Spanish Society of Rheumatology). ${ }^{1}$ Rheumatology, Hospital Universitario de Bellvitge, Hospitalet de LLobregat, Barcelona; ${ }^{2}$ Unidad de Investigacion, Sociedad Española de Reumatologia, Madrid; ${ }^{3}$ Rheumatology, Hospital Universitario Doctor Negrin, Las Palmas de Gran Canaria; ${ }^{4}$ Rheumatology, Hospital Universitario Gregorio Marañón; ${ }^{5}$ Rheumatology, Hospital Universitario 12 de octubre, Madrid; ${ }^{6}$ Rheumatology, Hospital Universitario Araba, Vitoria; ${ }^{7}$ Rheumatology, Hospital Universitario de Málaga., Malaga; ${ }^{8}$ Rheumatology, Hospital Germans Trias i Pujol, Badalona. Barcelona ${ }^{9}$ Rheumatology, Hospital Universitario Puerta de Hierro, Madrid; ${ }^{10}$ Rheumatology, Hospital Universitario Marqués de Valdecilla, Santander, ${ }^{11}$ Rheumatology, Hospital General Universitario de Alicante., Alicante; ${ }^{2}$ Rheumatology, Hospital Universitario Dr Peset, Valencia: ${ }^{13}$ Rheumatology, Hospital Universitario Reina Sofía;

${ }^{14}$ Rheumatology, Hospital Universitario La Paz; ${ }^{15}$ Rheumatology, Hospital Universitario Ramon y Cajal, Madrid; ${ }^{16}$ Rheumatology, Complejo Asistencial Universitario de León, Leon; ${ }^{17}$ Rheumatology, Complexo Hospitalario Universitario de A Coruña, La Coruña; ${ }^{18}$ Rheumatology, Hospital Universitario de Canarias, Tenerife; ${ }^{19}$ Rheumatology, Hospital Madrid Norte Sanchinarro; ${ }^{20}$ Rheumatology, Hospital Universitario de La Princesa, Madrid; ${ }^{21}$ Rheumatology, Hospital Insular de Gran Canaria, Las Palmas de Gran Canaria; ${ }^{22}$ Rheumatology, Hospital de Navarra, Pamplona; ${ }^{23}$ Rheumatology, Hospital Povisa, Vigo; ${ }^{24}$ Rheumatology, Hospital Son LLatzer, Mallorca; ${ }^{25}$ Rheumatology, Hospital Virgen de la Arrixaca, Murcia; ${ }^{26}$ Rheumatology, Hospital de Valme, Sevilla; ${ }^{27}$ Rheumatology, Hospital de Sant Pau, Barcelona; ${ }^{28}$ Rheumatology, Hospital Clínico Universitario de Salamanca, Salamanca; ${ }^{29}$ Rheumatology, Hospital Parc Taulí, Sabadell, Barcelona; ${ }^{30}$ Rheumatology, Hospital Miguel Servet, Zaragoza; ${ }^{31}$ Rheumatology, Hospital de Basurto, Billbao; ${ }^{32}$ Rheumatology, Hospital Universitario Príncipe de Asturias, Alcalá de Henares. Madrid; ${ }^{33}$ Rheumatology, Hospital Marina Baixa, Villajoyosa. Alicante; ${ }^{34}$ Rheumatology, Hospital Universitario Virgen de la Macarena, Sevilla; ${ }^{35}$ Rheumatology, Hospital Universitario de Donosti, San Sebastián; ${ }^{36}$ Rheumatology, Hospital Universitario Lucus Augusti, Lugo;

${ }^{37}$ Rheumatology, Complexo Hospitalario Universitario de Vigo, Vigo, Spain

Objectives: To investigate the primary respiratory manifestations (PRM) in SLE. Methods: All patients in the RELESSER cohort were retrospectively investigated for the presence of PRM

Results: At least one PRM was present in 11.3\% (365/3215) of cases. The most common was pleurisy, occurring in $21.1 \%$ of patients, followed by ALP in $3.6 \%$, $\mathrm{PE}$ in $2.9 \%$, PPH $4 \%$, DILD in $2 \%$, DAH in $0.8 \%$, and SLS in $0.8 \%$.

The variables associated with the presence of PPM are shown in the following table 1:

\begin{tabular}{lccc}
\hline & $\begin{array}{c}\text { Odds } \\
\text { Ratio }\end{array}$ & $\begin{array}{c}95 \% \\
\text { Confidence } \\
\text { Interval }\end{array}$ & $P$ \\
\hline Age & 1,03 & $1,02-1,04$ & 0.000 \\
SLEDAI score & 1,03 & $1,00-1,07$ & 0,02 \\
Raynaud phenomenon & 1,41 & $1,09-1,84$ & 0,01 \\
Severe nephritis & 1,56 & $1,18-2,06$ & 0002 \\
Secondary APS & 2,2 & $1,63-2,97$ & 0.000 \\
Anti-RNP positivity & 1,32 & $1,00-1,75$ & 0054 \\
Cardiac disease & 2,81 & $1,90-4,16$ & 0000 \\
Vasculitis & 1,81 & $1,25-2,62$ & 0002 \\
Hematologic abnormalities & 1,31 & $1,00-1,71$ & 0048 \\
Neuropsychiatric & 1,49 & $1,11-2.02$ & 0009 \\
manifestations & 2,05 & $1,14-3,67$ & 0016 \\
Gastrointestinal involvement & multivariable model, PPM remained a risk
\end{tabular}

After adjusting for known confounders in the multivariable model, PPM remained a risk

factor for diminished survival (HR: 3.13).

Conclusions: PPM independently contributed to a decreased survival in SLE Disclosure of Interest: None declared

DOI: 10.1136/annrheumdis-2018-eular.6436

\section{FRI0367 \\ ASSOCIATION OF VITALITY AND SUBSEQUENT PHYSICAL FUNCTIONING IN SYSTEMIC LUPUS ERYTHEMATOSUS: ANALYSIS OF DATA FROM THE GERMAN LULA COHORT $2002-2013$}

J. Mucke $^{1}$, G. Chehab ${ }^{1}$, R. Fischer-Betz ${ }^{1}$, J. Richter ${ }^{1}$, B. Winkler-Rohlfing ${ }^{2}$, M. Schneider ${ }^{1}$, R. Brinks ${ }^{1} .{ }^{1}$ Policlinic of Rheumatology and Hiller-Research Centre of Rheumatology, Heinrich-Heine-University Duesseldorf, Düsseldort, ${ }^{2}$ German Lupus Self-Help Community, Wuppertal, Germany

Background: Fatigue, defined as loss of vitality, is a major burden in patients with systemic lupus erythematosus (SLE). It is well-known from cross-sectiona studies that fatigue is associated with physical functioning (PF) whereas the effect of fatigue on subsequent PF has not yet been further looked on.

Methods: Data from the German Lupus-Langzeitstudie (LuLa) cohort was used to explore the effect of self-reported vitality on PF. The ongoing LuLa study com prises patients from the German SLE self-help group. The current analysis uses data from 2002 to 2013. We looked for associations between the PF score (outcome) and the vitality score of the SF-12 questionnaire in one to four years preceding the outcome. Statistical analysis was accomplished by a linear mixed regression model (LMM) adjusting for the potential confounders age, sex, disease duration and disease activity as surveyed by the Systemic Lupus Activity Questionnaire score (SLAQ).

Results: 1511 patients (93.3\% women) provided data with a total of 7841 personyears of observation. Median age at study entry was 46 (interquartile range: 37 to 57). The table 1 shows the regression coefficients of the vitality score (and 95\% confidence intervals, $\mathrm{Cl}$ ) estimated by the LMM without and with adjusting for age sex, disease duration and SLAQ.

\begin{tabular}{lcccc}
\hline $\begin{array}{l}\text { Exposure: Vitality scale } \\
\text { score }\end{array}$ & \multicolumn{2}{c}{ Crude estimates } & \multicolumn{2}{c}{ Adjusted estimates } \\
\cline { 2 - 5 } & $\begin{array}{l}\text { Estimate with } \\
95 \% \mathrm{Cl}\end{array}$ & $\mathrm{p}$-value & $\begin{array}{c}\text { Estimate with } \\
95 \% \mathrm{Cl}\end{array}$ & $\mathrm{p}$-value \\
\hline 1 year ahead & $0.08(0.05-0.10)$ & $<0.001$ & $0.07(0.05-0.09)$ & $<0.001$ \\
2 years ahead & $0.09(0.07-0.11)$ & $<0.001$ & $0.07(0.05-0.09)$ & $<0.001$ \\
3 years ahead & $0.05(0.03-0.08)$ & $<0.001$ & $0.05(0.03-0.07)$ & $<0.001$ \\
4 years ahead & $0.03(0.001-0.06)$ & 0.038 & $0.04(0.01-0.07)$ & 0.002 \\
\hline
\end{tabular}

Conclusions: We found evidence that self-reported vitality in patients with SLE is associated with PF in the subsequent years. The data indicate a "window of opportunity" for treating fatigue symptoms of up to four years for maintenance of PF.

Disclosure of Interest: J. Mucke: None declared, G. Chehab Grant/research support from: GlaxoSmithKline and UCB Pharma for performing the LuLa-study, R. Fischer-Betz Grant/research support from: GlaxoSmithKline and UCB Pharma for performing the LuLa-study, J. Richter Grant/research support from: GlaxoSmithKline and UCB Pharma for performing the LuLa-study, B. Winkler-Rohlfing: None declared, M. Schneider Grant/research support from: GlaxoSmithKline and UCB Pharma for performing the LuLa-study, R. Brinks: None declared DOI: 10.1136/annrheumdis-2018-eular.4889

\section{FRI0368 COMPARISON OF CLINICAL AND LABORATORY PROFILES IN 3575 SYSTEMIC LUPUS ERYTHEMATOSUS PATIENTS WITH AND WITHOUT SJÖGREN'S SYNDROME: DATA FROM A NATIONWIDE PATIENT REGISTRY (RELESSER)}

J.G. Ovalles-Bonilla ${ }^{1}$, F.J. López-Longo ${ }^{1}$, I. Rúa-Figueroa ${ }^{2}$, M. Galindo ${ }^{3}$, J. CalvoAlen $^{4}$, R.D. González ${ }^{1}$, B. Serrano ${ }^{1}$, I. Janta ${ }^{5}$, C. González ${ }^{5}$, I. Monteagudo ${ }^{5}$, J. C. Nieto ${ }^{5}$, J. Martínez ${ }^{5}$, C.N. Saenz ${ }^{5}$, J.M. Pego-Reigosa ${ }^{6}$, on behalf of RELESSER. ${ }^{1}$ Rheumatology, Hospital General Universitario Gregorio Marañón, Madrid; ${ }^{2}$ Rheumatology Division, Hospital Doctor Negrin, Las Palmas GC;

${ }^{3}$ Servicio de Reumatología, Hospital 12 de Octubre, Madrid; ${ }^{4}$ Rheumatology, Txagorritxu Hospital, Araba, Vitoria; ${ }^{5}$ Rheumatology, Hospital General Universitario Gregorio Marañón, Madrid; ${ }^{6}$ Rheumatology Section, Hospital de Meixoeiro, Pontevedra, Vigo, Spain

Background: The clinical coexistence of Systemic Lupus Erythematosus (SLE) and Sjögren's Syndrome (SS) was recognised in 1959. The prevalence of SS among patients with SLE varies considerably among the published studies $(10 \%-$ $30 \%$ ). There is still controversy as to whether or not SLE patients with overlapping SS have a distinct and significantly milder lupus.

Objectives: To address the clinical and serologic features of SLE and differences from SLE that occurs in overlap with SS.

Methods: A retrospective cohort of 3575 unselected SLE patients from 45 Rheumatology Units across Spain was evaluated for the presence of overlapping SS 
using the American-European consensus criteria. Cumulative clinical data were collected at the moment of the last assessment. Clinical and laboratory parameters in SLE patients with SS (SLEwSS) were compared with those in SLE patients without SS (SLEwoSS).

Results: SS was identified in 516 SLE patients (14.4\%). Compared with the SLEwoSS group, patients with SLEwSS were significantly older, had a higher frequency of mucocutaneous manifestations, Raynaud's phenomenon, peripheral neuropathy, anti-Ro/SSA, anti-La/SSB, neoplasia, and older age at death, but had a significantly lower frequency of renal involvement, thrombocytopenia, antiDNA, anti- $\beta 2$-GPI IgM and complement consumption. Both groups displayed a clinically similar presentation of lymphadenopathy, systemic vasculitis, serositis, damage accrual, mortality, musculoskeletal and CNS manifestations.

\begin{tabular}{|l|c|c|c|}
\hline \multicolumn{1}{|c|}{ FEATURES } & $\begin{array}{c}\text { SLEwSS } \\
\mathbf{N = 5 1 6}\end{array}$ & $\begin{array}{c}\text { SLEwoSS } \\
\mathbf{N = 3 0 5 9}\end{array}$ & $\mathbf{p}$ \\
\hline Age, years \pm SD & $54.2 \pm 14.9$ & $45.6 \pm 14.5$ & $<0.001$ \\
\hline Age at SLE onset, years \pm SD & $38.6 \pm 15$ & $32.1 \pm 14$ & $<0.001$ \\
\hline Female & 97.5 & 89.1 & $<0.001$ \\
\hline Lymphadenopathy & 11.8 & 10.0 & 0.233 \\
\hline Photosensitivity & 65.0 & 57.2 & 0.002 \\
\hline Oral ulcers & 55.8 & 42.7 & $<0.001$ \\
\hline Alopecia & 36.3 & 32.0 & 0.069 \\
\hline Raynaud's Phenomenon & 39.9 & 32.7 & 0.001 \\
\hline Systemic vasculitis & 9.6 & 8.4 & 0.352 \\
\hline Arthritis & 75.0 & 76.5 & 0.467 \\
\hline Myositis & 4.0 & 3.4 & 0.515 \\
\hline Fibromyalgia & 13.9 & 5.1 & $<0.001$ \\
\hline Pleurisy & 22.7 & 22.4 & 0.893 \\
\hline Pulmonary fibrosis & 2.3 & 1.9 & 0.563 \\
\hline Renal manifestations & 18.3 & 32.7 & $<0.001$ \\
\hline Seizures & 6.3 & 6.6 & 0.805 \\
\hline Peripheral neuropathy & 5.4 & 2.9 & 0.004 \\
\hline Hemolytic anemia & 7.1 & 8.6 & 0.272 \\
\hline Leucopenia & 55.6 & 53.5 & 0.428 \\
\hline Thrombocytopenia & 15.5 & 20.8 & 0.007 \\
\hline Anti-Ro/SSA & 69.2 & 34.4 & $<0.001$ \\
\hline Anti-La/SSB & 48.1 & 14.4 & $<0.001$ \\
\hline Anti-Sm & 19.8 & 21.2 & 0.495 \\
\hline Anti-RNP & 23.2 & 25.2 & 0.317 \\
\hline Anti-DNA & 55.9 & 65.1 & $<0.001$ \\
\hline Anti- $\beta 2-$-GPI IgM & 8.6 & 14.5 & 0.006 \\
\hline Antiphospholipid syndrome & 13.0 & 14.0 & 0.520 \\
\hline Hypocomplementemia & 62.3 & 69.0 & 0.012 \\
\hline SLICC-ACR DI & $1.19 \pm 1.8$ & $1.03 \pm 1.7$ & 0.062 \\
\hline Neoplasia & 7.8 & 5.5 & 0.042 \\
\hline Exitus & 7.2 & 6.0 & 0.324 \\
\hline Age at death, years \pm SD & $67.3 \pm 14.4$ & $54.2 \pm 18.0$ & $<0.001$ \\
\hline SLEwSS: Systemic lupus erythematosus with Sjögren's syndrome. SLEwoSS: Systemic \\
\hline lupus erythematosus without Sjogren's syndrome. SuCC-ACR DI: Systemic Lupus \\
\hline International Collaborating Clinics/American College of Rheumatology Damage Index. \\
\hline \multicolumn{1}{|c|}{ Except where indicated otherwise, values are the percentage. } \\
\hline & & & \\
\hline
\end{tabular}

Conclusions: SLEwSS appears to constitute a subgroup of SLE patients with distinct clinical and serologic features, in whom SS is expressed as an overlapping entity. A particular cluster of clinical variables, namely, mucocutaneous manifestations, Raynaud's phenomenon, peripheral neuropathy, renal involvement and thrombocytopenia, was found to be important overall for discriminating SLE patients with or without SS. SLEwSS patients constitute a subgroup of patients with SLE characterised by milder lupus: older age at death, similar rates of mortality and SLICC-ACR damage index, less renal and immunological manifestations. Disclosure of Interest: None declared

DOI: 10.1136/annrheumdis-2018-eular.6123

\section{FRI0369 PREGNANCY OUTCOMES IN WOMEN WITH ANTIPHOSPHOLIPID ANTIBODIES: INTERIM RESULTS FROM A SINGLE CENTRE COHORT STUDY}

K. Schreiber ${ }^{1,2}$, M. Frishman ${ }^{1}$, M.J. Cuadrado ${ }^{3}$, K. Breen ${ }^{1}$, S. Robinson ${ }^{1}$, B. J. Hunt ${ }^{1} .{ }^{1}$ Department of Thrombosis and Haemophilia, Guy's and St Thomas' Hospital, London, UK; ${ }^{2}$ Copenhagen Lupus and Vasculitis Clinic, Center for Rheumatology and Spine Diseases, Copenhagen University Hospital, Rigshospitalet, Copenhagen, Denmark; ${ }^{3}$ Department of Rheumatology, Guy's and St Thomas' NHS Foundation Trust, London, UK

Background: Persisting antiphospholipid antibodies (aPL) are associated with adverse obstetric events including recurrent miscarriage, late fetal loss or early delivery due to pre-eclampsia or placental insufficiency (obstetric APS) and also thrombosis. We are a tertiary referral centre for those with aPL, and have a management protocol for women with aPL during pregnancy and the puerperium with the aim of preventing obstetric complications and maternal thrombosis.

Objectives: To report the fetal and maternal outcomes from a single centre cohort of 511 pregnancies in 372 women over a period of eight years.

Methods: This is an ongoing retrospective observational study registered as an audit. Data was collected from clinic lists attending the pregnancy clinic at the Thrombosis centre of St. Thomas' Hospital in London, UK between Jan 2010 to December 2017. Women persistently positive for aPL were included if pregnancy outcome data was available.

Results: 511 pregnancies in 372 women were included in the study (table 1). The overall live birth rate was $78.9 \%$. Pregnancy outcomes are outlined in table 2 .

Abstract FRI0369 - Table 1. Demographics

\begin{tabular}{lc}
\hline Age in years, median (range) & $35(18-50)$ \\
\hline Ethnicity (white:black:asian:other:not specified) & $(186(50 \%): 17(5 \%): 35(9 \%): 94(25 \%): 40$
\end{tabular}

Antiphospholipid antibody profile at

$(11 \%))$

\section{diagnosis}

Lupus anticoagulant, $\mathrm{n}(\%)$ (dAPTT:DRVVT:

TSVT)

Anticardiolipin $\lg G$ and $\lg M, n(\%)$

$\beta 2$-glycoprotein-I IgG and IgM, $\mathrm{n}(\%)$

APS history

Obstetric APS (any), $\mathrm{n}(\%)$

Obstetric APS (1 st trimester loss), $n$ (\%)

Obstetric APS (2nd trimester loss), n (\%)

Fetal death (>24 weeks), $\mathrm{n}(\%)$

Intrauterine growth restriction, $\mathrm{n}(\%)$

Pre-eclampsia, $n$ (\%)

Thrombotic APS (any), n (\%)

Autoimmune profile

ANA:ENA:dsDNA, $n(\%)$

$261(70 \%)(183: 144: 27)$

$119(40 \%)$ and $144(39 \%)$

$16(4 \%)$ and $27(7 \%)$

$$
\begin{gathered}
125(34 \%) \\
74(20 \%) \\
35(9 \%) \\
19(5 \%) \\
30(8 \%) \\
19(5 \%) \\
106(29 \%) \\
(n=511)
\end{gathered}
$$

\begin{tabular}{|c|c|}
\hline Pregnancy outcomes & Total pregnancies, no511 \\
\hline \multicolumn{2}{|l|}{ Treatment during pregnancy } \\
\hline Appitin, $75 \mathrm{mg}$ doily, $n|\mathrm{~s}|$ & $500(24 x)$ \\
\hline Low molectres weigh heporin, $n(5)$ & $381(72 x)$ \\
\hline Npprin + Megarin & $357(200 x)$ \\
\hline Aspatin - Meperih - HCQ & $6(17 \%)$ \\
\hline Hydroxychloroquine, in: & $158(300 x)$ \\
\hline Neathioptine, n(6) & $521.006)$ \\
\hline Antihnoertencives, a(x) & $17(3 \times)$ \\
\hline Ssetoiles, $n(x)$ & $123(23 \times)$ \\
\hline Steroiles dose in me, menn 150, rangel & $\operatorname{tas}(-1 / 5,4,2-40)$ \\
\hline O12 supplenents,,$\{x\}$ & $13(3 \times)$ \\
\hline VeA priar to pegenanny, n(X) & $67(13 x)$ \\
\hline IVF treatment an $\left|x_{1}\right|$ & 69113\%) \\
\hline Pregnancy outcomes & (n=511) \\
\hline Lwe bints, $n(x)$ & $\cos (29 x)$ \\
\hline Twin pregnoncies & $23(36)$ \\
\hline Contational age at delivendweeks, reen|5D, angel & $33(0 \% / 2,25-80)$ \\
\hline Arthweigh $2550 \mathrm{~g}$ & $35(100 x)$ \\
\hline Brtheizh: $<5508$ & $\lambda(1 \mathrm{x})$ \\
\hline Brttweizht in gram, mean 150 , rongel & $3170+-1-315,575-53001$ \\
\hline Pregnancy bs, <10 wetes, n(x) & $70(126 x)$ \\
\hline 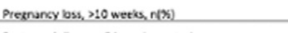 & $27(5 x)$ \\
\hline 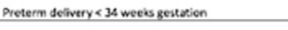 & $23(2.5 \%)$ \\
\hline Preteen deintery< 37 weés sestexion & 521:06) \\
\hline 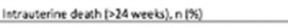 & $7(1 \times)$ \\
\hline Preedimpasis & $23(4 \times)$ \\
\hline Throrttosis durikg peregnance, $n|x\rangle$ & $9(4) \times)$ \\
\hline Caetarean sectioe, n ins) & $268(336)$ \\
\hline
\end{tabular}

$141(39 \%): 94(26 \%): 19(5 \%): 56$ (15\%)

Key: ANA, antinuclear antibodies, APS, antiphospholipid syndrome; aPL, antiphospholipid antibodies; aAPPT, dilute Activated Partial Thromboplastin Time; dRVVT, dilute Russe Viper Venom Time; dsDNA, doublestranded DNA, ENA, Extractable nuclear antigens, TSVT, Taipan Snake Venom Time

Abstract FRI0369 - Table 2. Pregnancy outcomes

Conclusions: These results from the largest single centre cohort reported show that using our management protocol, nearly $80 \%$ of women with aPL had a successful pregnancy outcome.

Disclosure of Interest: None declared

DOI: 10.1136/annrheumdis-2018-eular.7252 